\title{
Reduction of Kinematic Resistance To Movement Of the Railway Vehicles
}

\author{
E. Mikhailov ${ }^{1}, S$. Semenov ${ }^{1}, V$. Tkachenko $^{2}$ and $S$. Sapronova $^{2}$ \\ ${ }^{1}$ East-Ukrainian National University named after Vladimir Dal,Central ave., 59-a/303, 93400, Severodonetsk, Ukraine, \\ ${ }^{2}$ State University of Infrastructure and Technology, Kirilivska, 9/3, 04080, Kiev, Ukraine
}

\begin{abstract}
The aim of the work is to reduce the train rolling resistance to movement the railway vehicles. The article proves the expediency of changing the constructive scheme of railway vehicle wheel, which allows independent rotation their wheel mounting surface rolling and the guide surface (flange). There has been carried out the classification and analysis of the advantages and disadvantages of various structural schemes wheels of the railway vehicles. There has been analyzed the Features resistance to movement wheels of traditional and perspective constructive scheme. The obtained results allow drawing a conclusion about the possibility of a significant reduction in train rolling resistance to movement of railway vehicles with wheels perspective constructive scheme.
\end{abstract}

\section{Introduction}

The problem of reducing the level of force interaction between the vehicle and rail track is one of the most important problems of the rail transport.

The main share of energy recourses in rail transport (up to $75 \%$ of consumed electrical energy and fuel) is attributed to the haulage of train.

The expenditure of energy resources on haulage of train is directly related to the level of train rolling resistance to movement its locomotives and carriages.

Known theoretical and experimental studies in this direction are mainly related to the definition and refinement of empirical formulas for calculating the resistance to movement of certain types crews, the advantages of rotating bearings in front of plain friction bearings, and the coefficients of air resistance.

Analysis the components of total resistance to movement rail vehicles shows that the most promising direction of its reduction is the reduction of those components that are generated as a result of friction interaction of wheels and rails (kinematic resistance to movement) [1-6].

The research direction related to the determination of the possibility of influencing the level resistance to movement of the rail vehicles to structural improvements in their running parts (the radial of mounted wheels and bodies, the use of independently rotating wheels, the active control of guiding, etc.) is quite popular [7-12]

A number of scientific researches and developmental designs are known $[1,2,12,13]$, the results of which show the greater efficiency of rail vehicles in operation due to the fact that the designs of their running parts differed from traditional ones.
From the standpoint of generation of train rolling resistance to movement forces of the vehicle, this traditional mounted wheels design has a number of significant drawbacks that have been sufficiently fully disclosed in the works of a number of researchers [1, 2].

In case of two-point contacting wheel with rail (in the presence of the main and flange wheel contact), as a result of the parasitic power circulation in a closed loop, the «wheel flange - lateral face of top of rail - the running surface of rail-wheels thread» appears so-called differential kinematic resistance to movement.

Circular kinematic resistance to movement is the result of a group multi-contact interaction of the wheel system and mounted wheels with track in the course of guided movement in the rail track by circulating parasitic power within one mounted wheels or a group of mounted wheels united by a single frame.

A radical way to reduce the kinematic resistance to movement of rail vehicles is to reduce the level of circulation of parasitic losses by introducing decoupling points into the kinematic chains, which can be achieved through the use of new engineering proposal for mounted wheels and individual wheels.

Reduction of kinematic resistance to movement is possible with a decrease in the circulation of parasitic losses in a closed loop «wheel flange - lateral face of top of rail - the running surface of rail-wheels thread». Radical reduction of this circulation can be achieved only by changing the constructive scheme of a single wheel that allows independent rotation their mounting surface and guiding surface (flange).

It seems expedient to analyze the potential of using various structural schemes of the rail carriages in terms opportunities of reducing the kinematic resistance to movement.

\footnotetext{
* Corresponding author: mihaylov.evv@gmail.com
} 


\section{The Analysis of Constructive Schemes of Railway Carriages}

When considering the known constructive schemes of the wheels of rail vehicles, they all were conventionally divided into six classification groups according to the criteria for ensuring the corresponding degrees of freedom in the coordinate of rotation wheel and the guide surface (flange) relatively to the wheel mounting surface around a common axis of rotation wheel.

The presence or absence of these degrees of freedom largely determines the level of kinematic running resistance to movement wheels on the rail [21].

A conditional classification of structural schemes of wheels of rail vehicles is shown in Fig 1.

In the above conditional classification, the wheels of the traditional constructive scheme are referred to group A, in which the wheel mounting surface thread and its guide surface (flange) are made monolithically.

The level of kinematic resistance to movement of rail vehicles with such wheels is taken as $100 \%$.

Group B includes structural schemes of wheels in which, due to the use of elastomeric elements, there is the possibility of slight elastic displacements of the wheel mounting surface (tire) relative to the wheel centre.

The range of such constructive solutions is quite wide. In this direction, it should be especially noted a large complex of works on the creation of rubberized wheels, conducted by a team of researchers from the East Ukrainian National University named after V. Dahl, headed by prof. A. L. Golubenko for improving the dynamic and tractive characteristics of the vehicle, reducing the resistance to movement and reducing fretting wear of wheels and rails [1].

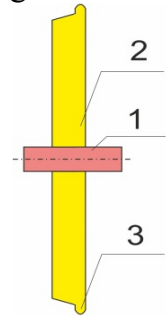

(A)

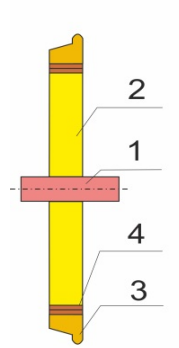

(D)

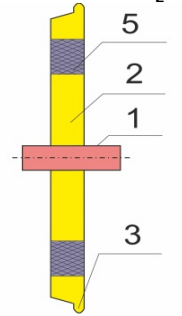

(B)

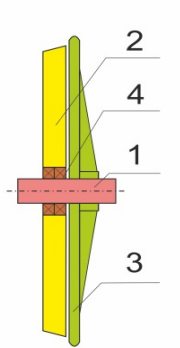

(E)

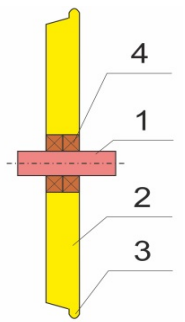

(C)

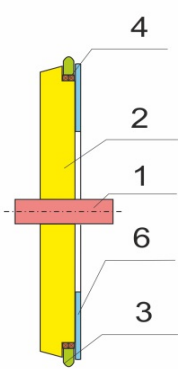

(F)
Fig. 1. Conditional classification of structural schemes of rail carriage wheels: 1 - axle; 2 - wheel center; 3 - flange; 4 bearing bush; 5 - elastomeric element; 6 - pressure disk

By reducing the roughness of the torsion coupling of the wheel mounting surface (tire) with wheel centers, it is possible to provide a certain reduction in the wobble frequency when driving in straight sections of the track, improve the dynamical and tractive characteristics of the vehicle.

However, the use of such wheels does not make it possible to compensate for the range difference traveled by the left and right wheel in the mounted wheels when operation in curves, to eliminate associated wheel sliding along the rails and additional resistance to movement.

According to the data [1], the use of the wheels of this group allows to reduce the circulation component of the kinematic resistance to movement of rail vehicles by 5 ... $8 \%$.

The use of the wheels of group C (so-called independently rotating wheels) in the truck of rail vehicles is a fairly well-known technical solution aimed at improving the dynamics and reducing the resistance to movement.

However, in the operation of rail vehicles with wheels of this constructive scheme, there are problems associated with insufficient guiding action of mounted wheels with such wheels when driving in a rail track.

This movement usually occurs with a prolonged twopoint contact of one of the wheels with a rail significant angle of attack and negative consequences in the form of increased wear of the ridges and resistance to movement.

One of the technical solutions implemented in real operation that eliminate to some extent this disadvantage is the Spanish technology "TALGO", which makes it possible to reduce the angles of the attack of independently rotating wheels due to the forced radial of the single-axle truck in which they are installed.

However, studies show that during the exploitation of the TALGO trains there are facts of heavy wear of the ridges due to the special character of the front uniaxial body entry in the curve with the realization of increased directional forces and, correspondingly, increased running resistance to movement.

Thus, in work [13] in analyzing the wear characteristics of the flanges of wheels, it was established that the flanges of the wheels of the end and inter-wagon bogies had wear, the average intensity being 2.01 and $0.95 \mathrm{~mm}$, respectively, for $20,000 \mathrm{~km}$.

In this case, the use of such structures can reduce the circulation component of the kinematic resistance to movement of rail vehicles up to $50 \%$.

So-called "wheels of differential rotation" [2, 14-17] developed by L.V.Vinnik can be attributed to a separate group of conditional classification (group D). The tire of such a wheel is mounted on the wheel centre by a free fit, which is actually a plain friction bearing.

Extensive theoretical studies of the features of the movement of rail vehicles with wheels of the proposed constructive scheme have shown the possibility of obtaining a positive effect in the form of reducing the resistance to movement and wheel thread and rails.

The disadvantage of the proposed technical solutions of the wheels of this group, despite the possibility of reducing the direct creep forces in the range of $28 \ldots$ $30 \%$ and the resistance to movement up to $12 \%$, is a wide variation under various conditions of force of friction between the moving bandage and the wheel center. 
At the same time, the claimed differential design effect may be appearing not in full.

In addition, there was severe wear on the contact surfaces of the wheel center and the tire.

This problem requires additional research, which, however, is recognized by the author their constructive scheme.

In the group $\mathrm{E}$ of conditional classification, constructive schemes of wheels are included, the feature of which is the possibility of independent rotation the wheel mounting surface and its guide surface (flange) relative to their common axis rotation.

One of the most successful designs of this group is development of the so-called "flexible wheels", conducted under the leadership of V.V. Shiller (Omsk State Transport University) [18, 19].

As a result of theoretical studies and tests on models, it is concluded that the use wheels of such constructive scheme can reduce the resistance to movement and reduce the cost of haulage of train up to $30 \%$, and in some cases-up to $50 \%$, while the wear of rails can be reduced to $30 \%$.At present, full-scale tests of the wagon with such wheels are carried out.

The group $\mathrm{F}$ of the conditional classification includes constructive schemes of the wheels, in which an independent rotation of the guide surface of wheel (its flange) is provided with respect to the wheel mounting surface, when the movable flange is mounted directly on the wheel.

When using wheels of such a constructive scheme in the composition of the carriage part of the railway rolling stock, the reduction of the differential component of the kinematic resistance to movement due to the reduction of parasitic slip in the flange contact can amount to $40 \%$.

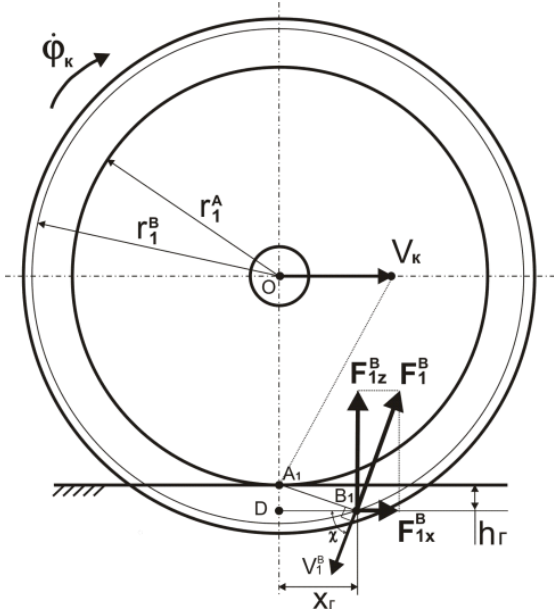

Fig. 2. Calculation scheme: a) wheel TKS; b) wheel PKS k

For the TKS wheel the module and the direction of the slip speed vector in the flange contact are uniquely determined by the geometric characteristics of the wheel and the rail and the angular speed of the wheel rotation.

When the wheel PKS moves, the direction and modulus of the slippage speed vector along the rail
Thus, the conducted analysis showed that the greatest decrease in the kinematic resistance to movement can be achieved by using the structural schemes of the wheels of groups $\mathrm{E}$ and $\mathrm{F}$ of the proposed conditional classification by reducing the parasitic slip and reducing decrease the power of creep forces in the flange contact of the wheel with the rail.

\section{The Features of Motion by Rail of Wheels of Different Constructive Schemes}

Obviously, in the case of a fundamental change in the constructive of the wheel (allowing the possibility of turning the guide surface (flange) to the wheel mounting surface around their common axle - then the wheel of the perspective constructive scheme - the PKS wheel), the character of its movement along the rail should change in comparison with the wheel of the traditional constructive scheme (hereinafter the wheel TKS).

The study of the peculiarities of movement along the wheel of traditional and perspective wheels of the constructive scheme for the case of point-to-point contact with the rail showed significant differences in the character of this movement.

This can be judged by considering the calculation schemes shown in Fig. 2, which show the directions of the vectors of the components of the slip speed and creep forces in the flange contact in the longitudinal vertical plane for the TKS wheel (Fig. 2a) and PKS (Fig. 2, b).

The analysis of theses schemes made it possible to establish the analytical dependencies of the module and the direction of the slip speed in the flange contact of the PKS wheel on the speed of wheel and the angle of attack to the rail.

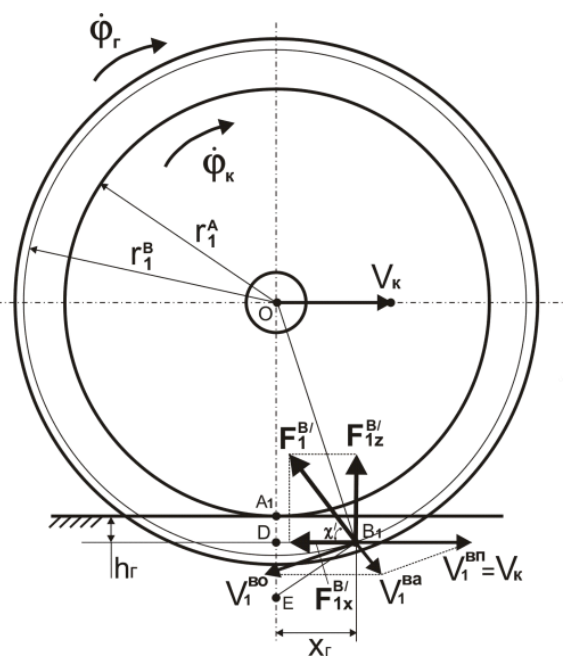

depend not only on the geometric parameters of the wheel and rail, but also on the ratio of the angular speeds of rotation the wheel mounting surface and guide surface of wheel (its flange) around a common axis of rotation wheel. Thus, for the calculation scheme of Fig. 2, in 


$$
\begin{aligned}
& \chi^{\prime}=\arcsin \left(\frac{\left(r_{l}^{A}+h_{\Gamma}\right) \cdot \operatorname{tg} \psi \cdot \operatorname{tg} \beta}{\sqrt{\left(\left(K_{w}-1\right) \cdot r_{l}^{A}-h_{\Gamma}\right)^{2}+\left(\left(r_{I}^{A}+h_{\Gamma}\right) \cdot \operatorname{tg} \psi \cdot \operatorname{tg} \beta\right)^{2}}}\right) \\
& V_{1}^{B A}=\stackrel{\&}{\varphi}_{k} \cdot \frac{\sqrt{\left(\left(K_{w}-1\right) \cdot r_{1}^{A}-h_{\Gamma}\right)^{2}+\left(\left(r_{1}^{A}+h_{\Gamma}\right) \cdot \operatorname{tg} \psi \cdot \operatorname{tg} \beta\right)^{2}}}{K_{w}} \\
& \chi^{\prime}=\arcsin \left(\frac{\left(r_{1}^{A}+h_{\Gamma}\right) \cdot \operatorname{tg} \psi \cdot \operatorname{tg} \beta}{\sqrt{\left(\left(K_{w}-1\right) \cdot r_{1}^{A}-h_{\Gamma}\right)^{2}+\left(\left(r_{I}^{A}+h_{\Gamma}\right) \cdot \operatorname{tg} \psi \cdot \operatorname{tg} \beta\right)^{2}}}\right) \\
& V_{1}^{B A}=\stackrel{\leftrightarrow}{\varphi}_{k} \cdot \frac{\sqrt{\left(\left(K_{w}-1\right) \cdot r_{1}^{A}-h_{\Gamma}\right)^{2}+\left(\left(r_{1}^{A}+h_{\Gamma}\right) \cdot \operatorname{tg} \psi \cdot \operatorname{tg} \beta\right)^{2}}}{K_{w}} \\
& \chi^{\prime}=\arcsin \left(\frac{\left(r_{1}^{A}+h_{\Gamma}\right) \cdot \operatorname{tg} \psi \cdot \operatorname{tg} \beta}{\sqrt{\left(\left(K_{w}-1\right) \cdot r_{I}^{A}-h_{\Gamma}\right)^{2}+\left(\left(r_{I}^{A}+h_{\Gamma}\right) \cdot \operatorname{tg} \psi \cdot \operatorname{tg} \beta\right)^{2}}}\right) \\
& \chi^{\prime}=\arcsin \frac{\left(r_{1}^{A}+h_{\Gamma}\right) \times \operatorname{tg} \psi \times \operatorname{tg} \beta}{\sqrt{\left(\left(K_{w}-1\right) r_{1}^{A} h_{\Gamma}\right)^{2}+\left(\left(r_{1}^{A}+h_{\Gamma}\right) \operatorname{tg} \psi \quad \operatorname{tg} \beta\right)^{2}}}
\end{aligned}
$$

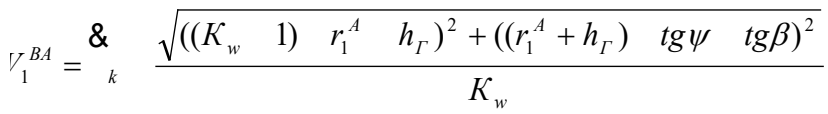

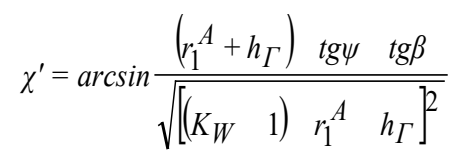

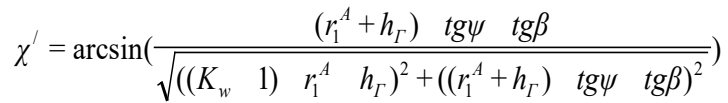

$$
\begin{aligned}
& V_{1}^{B A}=\stackrel{\leftrightarrow}{\varphi}_{k} \cdot \frac{\sqrt{\left(\left(K_{w}-1\right) \cdot r_{1}^{A}-h_{\Gamma}\right)^{2}+\left(\left(r_{1}^{A}+h_{\Gamma}\right) \cdot \operatorname{tg} \psi \cdot \operatorname{tg} \beta\right)^{2}}}{K_{w}} \\
& n^{2}=\frac{3 P^{\prime}}{4 \pi} \\
& n^{2}=\frac{3 P^{\prime}}{4 \pi} \quad\left(\begin{array}{cc}
L_{i}^{2}-L_{i+1}^{2} \\
F_{i} & F_{i+1}
\end{array}\right) \\
& b^{2}=\frac{4 \pi F_{i} n^{2} \quad 3 P^{\prime} L_{i}^{2}}{P^{\prime}}
\end{aligned}
$$

where $K_{W}=\phi_{K} / \& \&_{\Gamma} ; \psi$ - the angle of attack wheel to the rail; $\beta$ - the angle of inclination the generatrix the flange of wheel to the horizontal.

The ideal possibility of a complete absence of differential kinematic slip in the flange contact for such a wheel can be realized only if the following conditions are satisfied: the angle of wheel run-on to the rail ( ) is zero and a certain ratio of the angular speeds of the wheel and the wheel flange PKS $\boldsymbol{\phi}_{K} / \phi_{\Gamma}=K_{W}$, where $K_{W}$ is a coefficient depending on the geometric parameters contacting the wheel and rail.

In the absence of a rigid connection between the values of the angular speed of the wheel mounting surface PKS and its mounting surface (flange), to determine the stable state of the system under consideration we use the well-known principle of minimum energy dissipation.

This principle says that if not a single state of the system is admissible but a certain set of states that are consistent with conservation laws and constraints imposed on the system, then its state is realized which corresponds to a minimal increase in the entropy of the system or, what is the same, minimal energy dispersal.

Taking this into account, we can consider the quasistationary (stable) state of the system under consideration to be its state, in which the energy dispersal in the flange contact is minimal.

This state corresponds to the movement of the flange of the wheel PKS with the angular speed

$$
\& \rightarrow \& / K_{W}
$$

To assess the effectiveness of using the perspective constructive scheme of the wheel in terms of reducing the differential component of its kinematic resistance to movement, we determine how much the power of the creep forces in the flange contact can be reduced.

In order to do this, let's imagine the momentary highpower effect of creep forces as a dot product of vectors of the creep force vector in the center of the flanges contact $B_{1}$ and the vector of the corresponding instantaneous sliding speed of the point $B_{1}$ of the flange along the rail

$$
\begin{gathered}
N_{1}^{B}=\stackrel{'}{F}_{1}^{B} \cdot \dot{I}_{1}^{B}=F_{1}^{B} \cdot V_{1}^{B} \cdot \cos \delta \\
N_{1}^{B /}=\stackrel{\prime}{F}_{1}^{B /} \cdot \stackrel{\prime}{V}_{1}^{B A}=F_{1}^{B \prime} \cdot V_{1}^{B A} \cdot \cos \delta
\end{gathered}
$$

where $\delta$ - the angle between the lines of action of the corresponding vectors.

With the glance of the fact that the force vector of the creep is directed opposite to the vector of the corresponding instantaneous speed, i.e. $\delta=\pi$ and $\cos \pi=-1$, in our case

$$
\left|N_{1}^{B}\right|=F_{1}^{B} \cdot V_{1}^{B}, \quad\left|N_{1}^{B \prime}\right|=F_{1}^{B \prime} \cdot V_{1}^{B A} .
$$

Let us estimate the possible relative decrease in the power of the creep forces in the flange contact for the wheel PKS by the coefficient $K_{N}$ :

$$
K_{N}=\frac{N_{1}^{B}-N_{1}^{B \prime}}{N_{1}^{B \prime}} \cdot 100 \%
$$

where $N_{1}^{B}$ and $N_{1}^{B /}$ - the power of creep forces in the flanges contact when moving, respectively wheel TKS and wheel PKS.

The general character of the dependence of the coefficient on the main influencing factors-the angular speed of the movable flange \& (at a fixed angular speed the wheel mounting surface $\&$ ) and angle of attack the wheel on the rail $\psi$ is shown in Fig. 3 . 
The calculation is made for the following traffic conditions: linear speed of the wheel $V_{K}=20 \mathrm{~m} / \mathrm{s}$, wheel radius $0,475 \mathrm{~m}$, magnitude the frictional force of creep in flange contact $F_{1}^{B}=12500 \mathrm{~N}, K_{W}=1,021$.

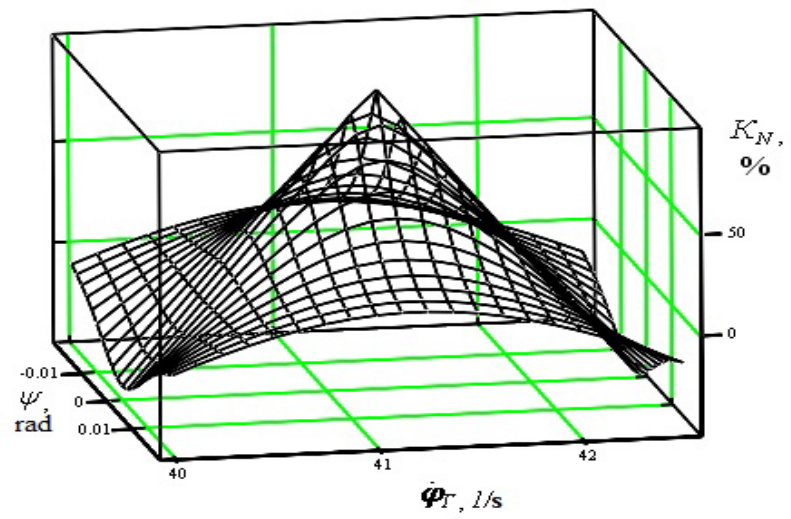

Fig. 3. Dependency graph $K_{N}=f(\not \&, \psi) \quad\left(V_{K}=20 \mathrm{~m} / \mathrm{s}\right.$, $\left.F_{1}^{B}=12500 \mathrm{~N}\right)$

The analysis of the graph in Fig. 3 shows that for ideal conditions for the movement of the wheel $\left(\&_{\Gamma} \rightarrow \phi_{\kappa} / K_{w}\right.$ and $\left.\psi \rightarrow 0\right)$, a virtually $100 \%$ reduction in the power of the creep forces in the flange contact for the PKS wheel in comparison with the TKS wheel is possible.

In real conditions the motion of wheel, due to the action of inertial forces and the moment of resistance to movement at the node of its interlinkage the wheel mounting surface and guide surface of wheel (its flange), and also with the practical impossibility of constant and strict observance of the condition, the resulting effect in the form of a decrease in the power of the creep forces in the flange contact will obviously be somewhat less.

Studies to assess the safety of the derailment of the wheel from the rail while rolling the ridge onto the rail made it possible to establish that the conditions for the implementation of the beginning of the process of derailing the wheel from the rail when rolling in the ridge are almost identical for the wheels of both structural schemes.

A significant difference is that the rolling of the wheel PKS on the head of the rail with the detachment of the rolling surface of the wheel from the surface of the

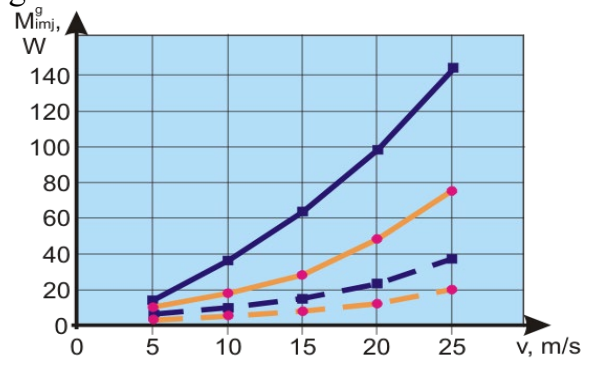

a) empty wagon rolling of the top of rail at the angles of attack the wheel on the rail more than $0.1 \mathrm{deg}$. is almost impossible, because under the influence of a system of applied forces and moments, the guide surface of wheel (its flange) will tend to turn of wheel mounting surface in the opposite side.

\section{The Investigation of Resistance to Movement the Motion of the Fourth Gondola Wagon with Wheels of Different Constructive Schemes}

In order to study the possibilities of reducing the resistance to movement of rail vehicles by using a promising constructive scheme in their trucks, a mathematical model [20] was simulated that imitates the movement along the railroad of a four-axle freight gondola wagon on a three-piece truck.

Satisfactory qualitative and quantitative coincidence of estimated and experimental data confirmed the suitability of the mathematical model not only for determining the dynamic index of the wagon, but also for the resistance to movement, because the work of creep forces at points of contact of wheels with rails cannot be measured directly.

There are results of calculations on mathematical models of some indicators of resistance to movement of four-axle gondola wagons for various modes of their movement below.

In Fig. 4-7 there are graphs of the dependence of the creep power $M_{i m j}^{g}$ in the flange contact of the approaching wheels (1st and 3rd mounted wheels of wagon) with wheels of different constructive schemes from the speed of movement in the loaded and empty states in the straight and curved sections of the curved track.

The figures are: TKS1, TKS3 - data for the 1st and 3rd mounted wheels with wheels of the traditional constructive scheme, PKS1, PKS3 - data for the 1st and 3rd wheel sets with the wheels of the perspective constructive scheme.

In the curved track, the value of the indicator $M_{i m j}^{g}$ was determined as the average power level of the corresponding creep forces in the flange contacts when the motion was steady.

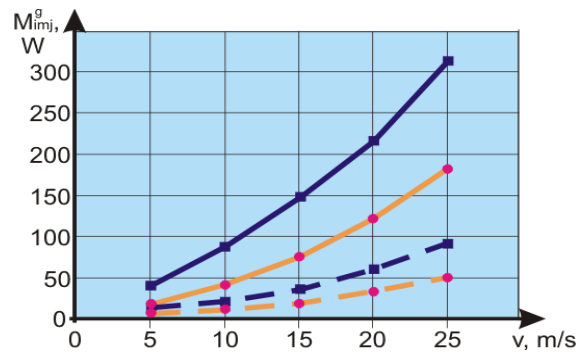

b) loaded wagon

\section{TKS1;}

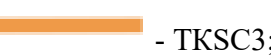

Fig.4. Dependences of the creep forces power $M_{i m j}^{g}$ in the flange contact of the foul wheels from the speed of the wagon $V$ (straight track) 


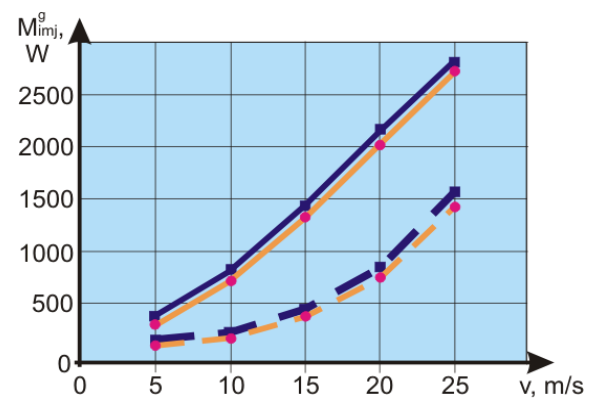

a) empty wagon

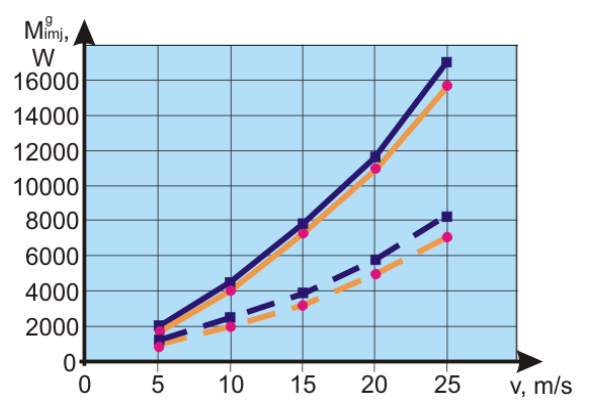

b) loaded wagon

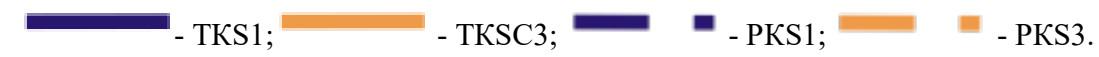

Fig.5. Dependences of the creep forces power $M_{i m j}^{g}$ in the flange contact of the foul wheels on the speed of the wagon $V$ (curve with a radius of $350 \mathrm{~m}$ )

Since in the straight section of the path the effect of creep forces power in flanges contact due to the wobble of the mounted wheels was periodic, so the corresponding values of the power level of the creep

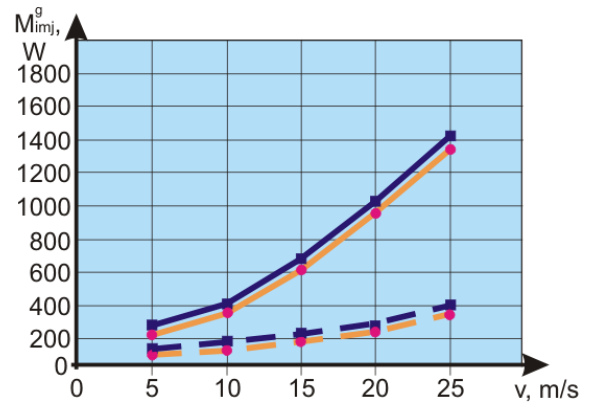

a) empty wagon forces for this mode of motion were averaged over by the maximum values of this power for the periods of contact of the corresponding flanges with the side faces the top of rail.

- TKS1;

- TKSC3;

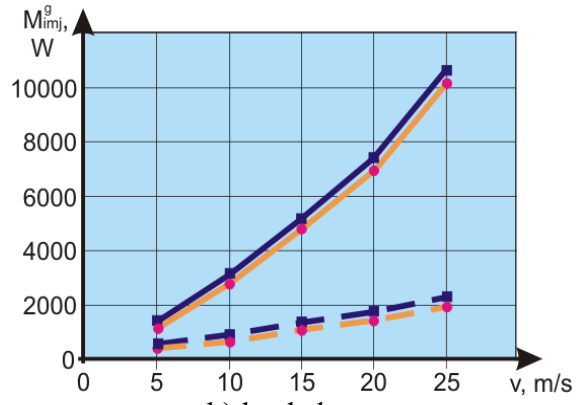

b) loaded wagon

Fig.6. Dependences of the creep forces power $M_{i m j}^{g}$ in the flange contact of the foul wheels on the speed of the wagon $V$ (curve with a radius of $750 \mathrm{~m}$ )
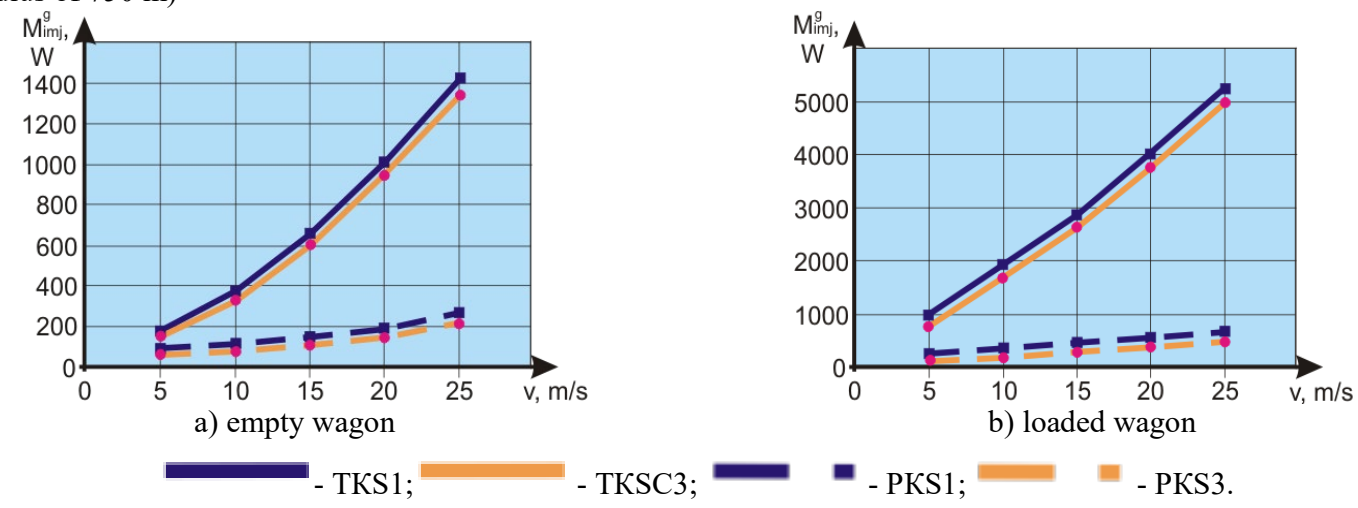

Fig.7. Dependences of the creep forces power $M_{i m j}^{g}$ in the flange contact of the foul wheels on the speed of the wagon $V$ (curve with a radius of $1200 \mathrm{~m}$ )

Analysis of the results of calculations showed the possibility of a significant reduction in the of creep forces power in the flange contacts, which determines one of the most important components of total resistance to movement of the wagon, when using the PKS wheels in the truck of a four-axle freight gondola wagon compared to using TKS wheels.

The calculated values of the total resistivity for the movement of an empty and loaded car with PKS wheels in different driving modes are obtained lower than the values of this index for a wagon with TKS wheels under the same conditions.

In the straight sections of the track, this decrease is $10 \ldots 12 \%$ for a loaded wagon and $13 \ldots 15 \%$ for an empty wagon depending on the speed of movement.

In curves with a radius of $350 \mathrm{~m}, 750 \mathrm{~m}$ and $1200 \mathrm{~m}$, respectively $20 \ldots 22 \%$ and $23 \ldots 25 \%, 16 \ldots 18 \%$ and $17 \ldots 19 \%, 13 \ldots 15 \%$ and $14 \ldots 16 \%$. 
In determining the possible savings in working expenditure due to the introduction of the wheels of the perspective constructive scheme in the truck of the fouraxle general-purpose gondola cars, in comparison with traditional wheels, according to the real operating conditions of the South-Western railway, the projected forecasted value of the net discounted income from the introduction of mounted wheels with wheels of the perspective constructive scheme in the amount of $E=14,85$ UAH million, which in terms of one wagon makes up $\Delta \mathrm{E}=29,7 \mathrm{UAH}$ thousand. At the same time, the estimated payback period of the project is $T_{O K}=4,1$ year.

\section{Conclusion}

The generalization of the obtained results allows us to conclude that a radical decrease in the creep forces power in the flange contact of the foul wheels during point-to-point contacting may be achieved by changing the structural scheme of the wheel of the rail carriage allowing independent rotation of its bearing support surface and the director plane (flange).

The use of wheels of such a constructive scheme in the trucks of rail vehicles can allow reducing the total resistance to movement by minimizing the differential component of the kinematic resistance to movement with a decrease in slippage of the wheel flanges along the rails, which will make it possible to significantly reduce the power consumption for hauling operations with such rolling stock.

\section{References}

1. M. Mitsche, Theory of Vehicle. Dynamic of Vehicle. Tom 2 Vibrations., 266 p. (1987)

2. J. Reimpell, Podwozia Samochodow: Podstawy Konstrukcji., 411 s. (1997).

3. A. Rutka, J. Sapragonas Mechanika 1 (33) pages 4148. (2002)

4. J.L. Swayze, B.I. Bachrach, S.R. Shankar Suspension Force Optimization Using Quarter-Car Model with Elastomeric Elements. Vol. 2: 785-795. (1999)

5. V. Tkachenko, S. Sapronova, I. Kulbovskyi, O. Fomin, Eastern-European journal of enterprise technologies. 5/7 (89). 65-72 (2017)
6. S. Sapronova, V. Tkachenko, O. Fomin, V. Gatchenko, S. Maliuk, Eastern-European journal of enterprise technologies, 6/7(90). 19-25 (2017)

7. P. Lukaszewicz, Doctoral Thesis. Stockholm. 154 p. (2001)

8. H. Kobayashi. Quarterly Report of RTRI. Nr. 1: 16-20. (2000)

9. R. Upadhyay. Reduced wear wheels and rails. International Railway Journal. 7. 33-34. (2000)

10. M.I. Spiryagin, V.I. Spiryagin, A.S. Klyuev, S.A. Klyuev, V.A. Ulshin TEKA Commission of Motorization and Energetics in Agriculture. 8a. 142-149. (2008)

11. A. Golubenko, A. Malohatko, S. Klyuev, TEKA Commission of Motorization and Energetics in Agriculture.11a. 5-12. (2011)

12. V.A. Ulshin, S.A. Klyuyev, TEKA Commission of Motorization and Energetics in Agriculture. 14, 1. 320-331. (2014)

13. M.C. Duffy, Electric Railways. 452 p. (2003)

14. A.M. Brzhezovsky, A.G. Parchevsky, M.S. Tikhov, Dynamics and impact on the way of passenger wagons of the company «PATENTES TALGO S.A.» with passive body inclination in curves. Bulletin of VNIIZhT. 2. 10-18 (2007)

15. G.P. Bourtchak, L.V. Vinnik,. Euromech colloquium 409. 34-35. (2000)

16. G.P. Bourtchak, L.V. Vinnik, Proceedings of the 7th Miniconference on Vehicle System Dynamics Identification and Anomalies (VSDIA 2000). 185193. (2001)

17. L. Vinnik, G. Bourtchak, D. Pogorelov, Proceedings of the 18th IAVSD Symposium held in Kanagawa. 41.. 607-616. (2003)

18. L.V. Vinnik, Second International workshop on freight vehicle design. 118-124. (2001)

19. A. Shiler, Proceedings of the 25th DAAAM International Symposium Procedia Engineering. 1714-1723. (2014)

20. I. Galiev, A. Shiler, A. Kildibekov, I. Kukushkin Proceedings of the 25th DAAAM International Symposium Procedia Engineering. 1724-1731. (2014)

21. A.G. Reidemeister PhD thesis. 185 p (2000) 